\title{
A Study of Population Size and Activity Patterns and Their Relationship to the Prey Species of the Eurasian Lynx Using a Camera Trapping Approach
}

\author{
Xiaoming Tang ${ }^{1,+}$, Shupei Tang ${ }^{1,+}{ }^{,}$Xiaoyu Li $^{2}$, Dalai Menghe ${ }^{3}$, Wuliji Bao ${ }^{3}$, Changlin Xiang ${ }^{3}$, \\ Fuli Gao ${ }^{1}$ and Weidong Bao ${ }^{1, *(1)}$ \\ 1 College of Biological Sciences and Technology, Beijing Forestry University, Beijing 100083, China; \\ tangxm@idsse.ac.cn (X.T.); tangshupei@outlook.com (S.T.); fuligao@bjfu.edu.cn (F.G.) \\ 2 Chifeng Academy of Forestry Sciences, Chifeng 024000, China; yuzi_kuaile@126.com \\ 3 Inner Mongolia Saihanwula National Nature Reserve Administration, Daban 025150, China; \\ mengdalai2009@163.com (D.M.); 13694759519@139.com (W.B.); xiangchl0612@sina.com (C.X.) \\ * Correspondence: wdbao@bjfu.edu.cn \\ + Same contribution first author.
}

Received: 18 October 2019; Accepted: 23 October 2019; Published: 25 October 2019

Simple Summary: The Eurasian lynx has a wide distribution range in China, but lynx field studies in China are rare compared to those for European populations. Using camera trapping data, this paper reports the lynx population size, activity patterns, and variation within the prey community at a nature reserve in Inner Mongolia. The results found that there were at least 20 lynx in this reserve, and the population has increased steadily over years. There is a seasonal difference in the daily activity rhythms of lynx. The total activity rhythm of lynx is synchronous with five mammal species: hare, red deer, wild boar, raccoon dog, and badger. Red fox and roe deer showed a timed avoidance of lynx to some extent. The present study sets an example for biodiversity conservation; the recovery of prey communities through habitat management should be a priority in determining the restoration of large carnivore populations in China.

\begin{abstract}
Revealing the behavioral relationships between predators and their prey is fundamental in understanding the community structure and ecosystem functions of such animals. This study aimed at detecting the population size and activity patterns of Eurasian lynx (Lynx lynx) (along with its prey) by camera trapping monitoring from 2014 to 2017 at the Saihanwula nature reserve in central Inner Mongolia. The total effective trapping days were 29,892 and 20 lynx were identified from 343 trapping photos based on the inner side patterns of their forelimbs. The daily activity rhythms of the lynx overlapped with those of different prey in different seasons. The yearly activity pattern of the lynx was influenced by its main prey's biology. In conclusion, this study reveals that the activity patterns of the top predator matched those of its prey in different time periods. Habitat management strategies promoting the restoration of prey communities would benefit the lynx in maintaining a stable community structure.
\end{abstract}

Keywords: activity pattern; camera trapping; Lynx lynx; meso-carnivores; prey community

\section{Introduction}

Detailed information on population sizes and activity rhythms is crucial in understanding species ecology, adaptation to the environment, and reasonable management strategies for biodiversity conservation. As an important aspect in behavioral ecology, activity pattern studies show animals' behavioral responses to their environmental factors, including other members in the community [1]. 
The elusive activity of nocturnal wild cats has made them difficult to study with traditional direct field survey and behavioral techniques [2]. With the quick development of technology such as camera trapping, an effective non-invasive approach, such works are made more feasible for wild cat species [3-5]. Several camera-trapping-based field works have been conducted on large wild cat species in China, such as snow leopard (Panthera uncia) [6-9], common leopard (Panthera pardus) [8,10], and Amur tiger (Panthera tigris altaica) [10,11], which appear in a variety of studies. However, similar camera trapping studies are still needed for other wild cats that urgently require systematic study and protection, including the Eurasian lynx (Lynx lynx, called lynx for short).

Eurasian lynx is a wide-spread cat species in Eurasia, including the Scandinavian Peninsula. In Europe and Siberia, field studies on lynx flourished rapidly post World War II, with a number of comprehensive efforts [12-21]. At present, European Union member states have established a long-term dynamic monitoring system and local area information sharing platform (http://scandlynx.nina.no/) to strengthen conservation. In China, the lynx is listed as a Chinese class II state key protected species and has a large distribution range in China, including in the northeast, northwest, and Tibetan plateau [22-24]. Other than a series of studies done by our research group in the Saihanwula national nature reserve, Inner Mongolia [25-28], only a few sporadic traditional transection surveys on lynx have been carried out in the Xinjiang Uygur Autonomous Region and northeastern area [29-31]. Therefore, many types of information are lacking for lynx in China. These characteristics include abundance and activity rhythms. The lynx population in China went through a sharp decline (over two-fold) in size (from 70 thousand to 27 thousand) from the 1970s to 1990s due to over exploitation, poaching, and habitat degradation [22]. For instance, in the 1980s-1990s, the sighting records of live lynx were exceedingly rare (only three records) in the Saihanwula reserve [32]. In the Changbaishan nature reserve, Jilin Province, the density of lynx fell from $0.023 / \mathrm{km}^{2}$ in the 1980 s to $0.008 / \mathrm{km}^{2}$ in the 1990s, and lynx almost disappeared in this area [22]. Thus, the lynx population in China is in danger and it is necessary to establish a long-term monitoring program for lynx populations for purposes of conservation and management. How has the abundance of lynx changed in different habitats over recent years? What is their current status? Currently, these critical questions cannot be answered due to the extreme lack of research on lynx in China. To solve this problem, we require systematic, long term, and species-targeted ecological research programs. A long-term lynx monitoring program has been conducted by our research group at the Saihanwula reserve since 2006, emphasizing population status, restoration, and habitat management. In order to track the abundance trend and status of the lynx in the nature reserve, multiple study approaches were adopted, among which camera trapping has been used since 2009 [25]. There are two objectives of the present paper. Firstly, we seek to update the latest information for the population size and status of lynx in Saihanwula based on camera trapping. Secondly, we desire to study the relationships between lynx and its eight sympatric mammal species through the activity patterns generated from camera trapping. The information provided from our survey will benefit the conservation and management of the lynx in this nature reserve.

\section{Materials and Methods}

\subsection{Study Area}

The Saihanwula national nature reserve is situated in the central part of Inner Mongolia, China $\left(118^{\circ} 18^{\prime}-118^{\circ} 55^{\prime} \mathrm{E}, 43^{\circ} 59^{\prime}-44^{\circ} 27^{\prime} \mathrm{N}\right)$, with an average altitude over $1000 \mathrm{~m}$. It covers about $10.04 \times 10^{4}$ ha of land that consists of forest, scrubland, meadow, and agricultural vegetation. Other than lynx, a diversity of mammal species inhabits Saihanwula. Among them, there are predators, such as wolf (Canis lupus), red fox (Vulpes vulpes), manul (Otocolobus manul), raccoon dog (Nyctereutes procyonoides), and badger (Meles leucurus). Large- and medium-sized prey includes red deer (Cervus xanthopygus), goral (Naemorhedus griseus), roe deer (Capreolus pygargus), wild boar (Sus scrofa), and hare (Lepus tolai) [32]. There are three core areas where most human activities (grazing, hunting, farming, and so forth) are forbidden by relevant regulations. Two of these core areas, Shenshan (SS) and Qingyunshan 
(QYS), were chosen as the sites for this study because of their high frequency of lynx occurrences. The former place occupies an area of 4766 ha and the latter occupies 5745 ha. These two areas are separated by a distance of $20 \mathrm{~km}$ and are both covered mainly by woodland and grassland (Figure 1).

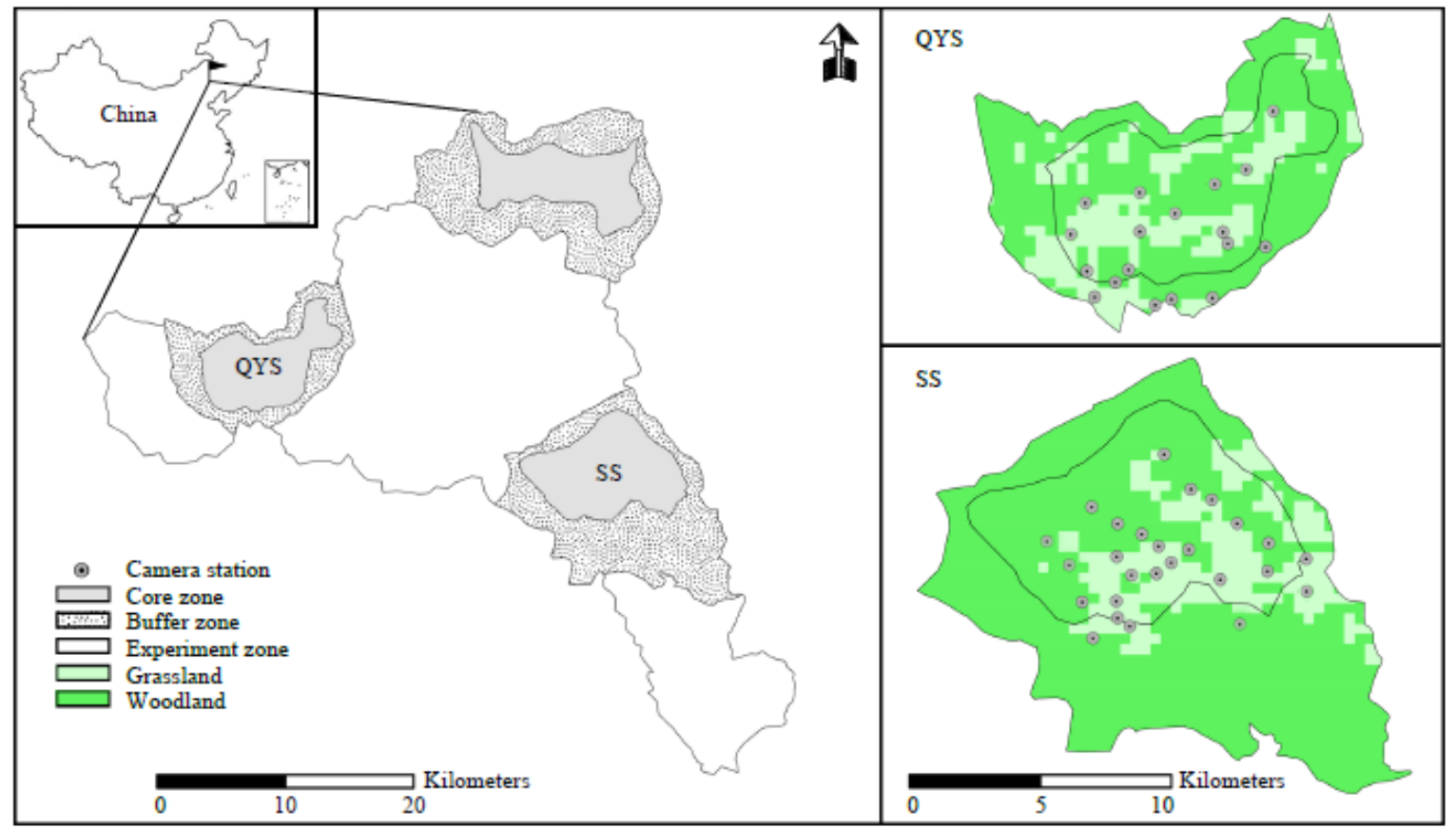

Figure 1. Location of the Saihanwula nature reserve and camera trapping sites.

\subsection{Camera Trapping Deployment and Data Analyses}

From January 2014 to December 2017, about 50 digital cameras (LTL-5210, Lieke Technology Co. Limited, Shenzhen, China) were positioned in the study area. These monitoring sites were decided mainly based on previous snow tracking, transection surveys, and camera studies. That is, the cameras were mainly placed around positions where lynx had been pictured or left their snowy footprints and feces. After these positions were set, the remainder of the camera was placed around sites where ungulates appeared frequently. The distance between any two camera sites was greater than $1 \mathrm{~km}$. The cameras were also moved when the animals were barely pictured at their original sites or there were new places with traces of lynx. In total, there were 44 different sites, which covered most of the area of SS (26 cameras) and the southern part of QYS (18 cameras) (Figure 1). The inner forelimb markings of the lynx were used for individual identification in this study (examples are shown in Figure S1). For this purpose, cameras were attached perpendicular to the animal route and at around $30 \mathrm{~cm}$ above the ground, and slight adjustments were made in accordance with the vegetation growth conditions in different seasons. The photographical pattern was set to take one photo, followed by a $15 \mathrm{~s}$ video with an interval of $1 \mathrm{~min}$ and was left working all day. Our lynx did not show any fear from the infrared lights and the operators' odor left on the digital cameras; some individuals even marked their visits by urinating on the camera fixing trees. The cameras were checked once a month, and the SD cards and batteries were replaced.

When checking the photos and videos, once an animal appeared, detailed information was recorded, including the location, date, time, numbers in the group, and behaviors.

For the activity rhythm, each occurrence (photos and videos) is regarded as one single independent capture (IC). The relative IC (RIC) was used to compare the yearly and daily activity patterns. The formulas of the RIC are as follows:

$$
\text { yearly RIC }=\frac{\text { IC of particular year }}{\text { camera trap day of particualr year }} \times 1000
$$




$$
\begin{gathered}
\text { monthly RIC of other animals }=\frac{\text { IC of particular month }}{\text { camera trap day of particualr month }} \times 100 \\
\text { monthly RIC of lynx }=\frac{\text { IC of particular month }}{\text { camera trap day of particular month }} \times 1000 \\
\text { daily RIC }=\frac{\text { IC of particular time phase }}{\text { total IC }} \times 100
\end{gathered}
$$

For the daily activity rhythm, the time phase was one hour. For example, 0:00-0:59 was time phase No. 0, and 1:00-1:59 was time phase No. 1. To compare the daily activity rhythms in different seasons, the study years were divided into four seasons: spring (March-May), summer (June-August), autumn (September-October), and winter (November-February next year). Fridenman's test was applied for a comparison amongst the different seasonal daily activity rhythms of the lynx. While for the activity rhythms of the lynx and its prey species, Pearson correlation tests were used, with $p<0.05$ as the significance level.

\section{Results}

\subsection{Population Abundance}

A sampling effort of 29,892 camera-days with 343 independent capture cases of lynx was obtained from 2014 to 2017 (Table 1). The total RIC was 11.47, and there were 10 lynx groups during the four study years. At least 20 lynx had lived in the whole study area with a density of $27.14 / 100 \mathrm{~km}^{2}$. In 2014 , five lynx groups were pictured, including a mother-kitten pair that had been photographed twice, a female individual taking the sub-adults, and two sibling groups, both featuring two individuals. However, in 2015, the RIC decreased acutely to 8.02, and no groups were found. In 2016, the RIC recovered, and one sibling group was recorded. For 2017, the RIC of 14.06 reached its highest point during the survey years.

Table 1. Yearly relative independent capture and abundance of lynx based on camera trapping.

\begin{tabular}{ccccccc}
\hline Year & Trap Days & IC & Yearly RIC & $\begin{array}{c}\text { Min. Numbers } \\
\text { in SS }\end{array}$ & $\begin{array}{c}\text { Min. Numbers } \\
\text { in QYS }\end{array}$ & No. of Groups \\
\hline 2014 & 8357 & 94 & 11.25 & $\geq 5$ & $\geq 7$ & 5 \\
2015 & 7606 & 61 & 8.02 & $\geq 7$ & $\geq 1$ & 0 \\
2016 & 5395 & 68 & 12.60 & $\geq 5$ & $\geq 3$ & 1 \\
2017 & 8534 & 120 & 14.06 & $\geq 5$ & $\geq 6$ & 4 \\
Total & 29,892 & 343 & 11.47 & $\geq 10$ & $\geq 10$ & 10 \\
\hline
\end{tabular}

IC: Independent capture; RIC: Relative independent capture; SS: Shenshan; QYS: Qingyunshan.

According to the videos taken in this work, the lynx did not show any fear of the infrared light or the scent of the camera operators. Indeed, the lynx approached the cameras and sometimes even left urine marks around them. Thus, the camera trapping technique is suitable for monitoring lynx activity.

\subsection{Distribution of Lynx}

The position of lynx family groups showed that the distribution was quite dispersive, with only one site that had over 15 records and two family sites found in QYS (Figure 2). In comparison, the family sites were more focused, with high frequency sites in the middle part of SS. 


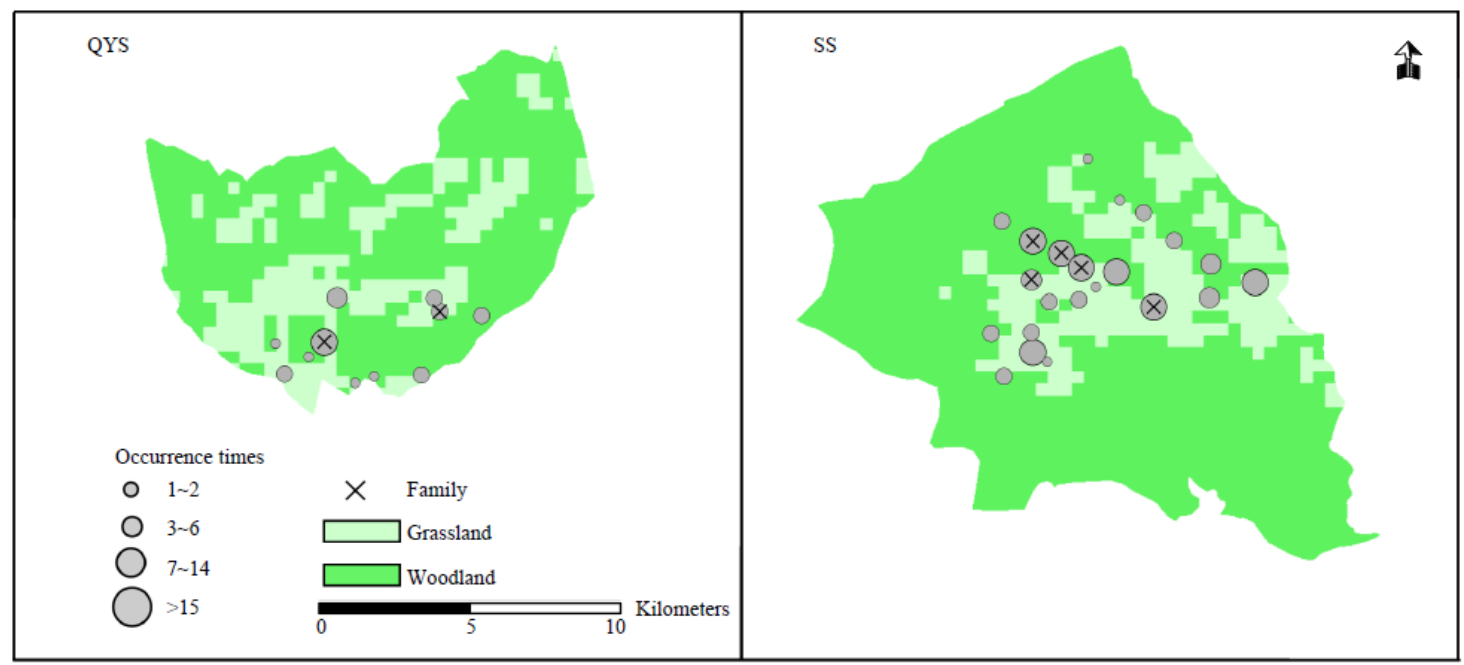

Figure 2. Distribution of independent captures and family sites for the lynx in Qingyunshan (QYS) and Shengshan (SS).

\subsection{Activity Rhythm of Lynx}

\subsubsection{Monthly Activity Rhythm}

Lynx presented a monthly bimodal pattern, with two peak periods overlapping with the herbivores' active peaks to a certain degree (Figure 3). The main peak of lynx started in February and ended in May, which was also the peak month for roe deer, red deer, and hare. The second peak of the lynx's yearly active pattern appeared in September and October, with the September peak overlapping with the wild boar and the October peak overlapping with the red deer. The less active months for the lynx in Saihanwula were June, July, August, and December. When it came to December, all species showed low activity.

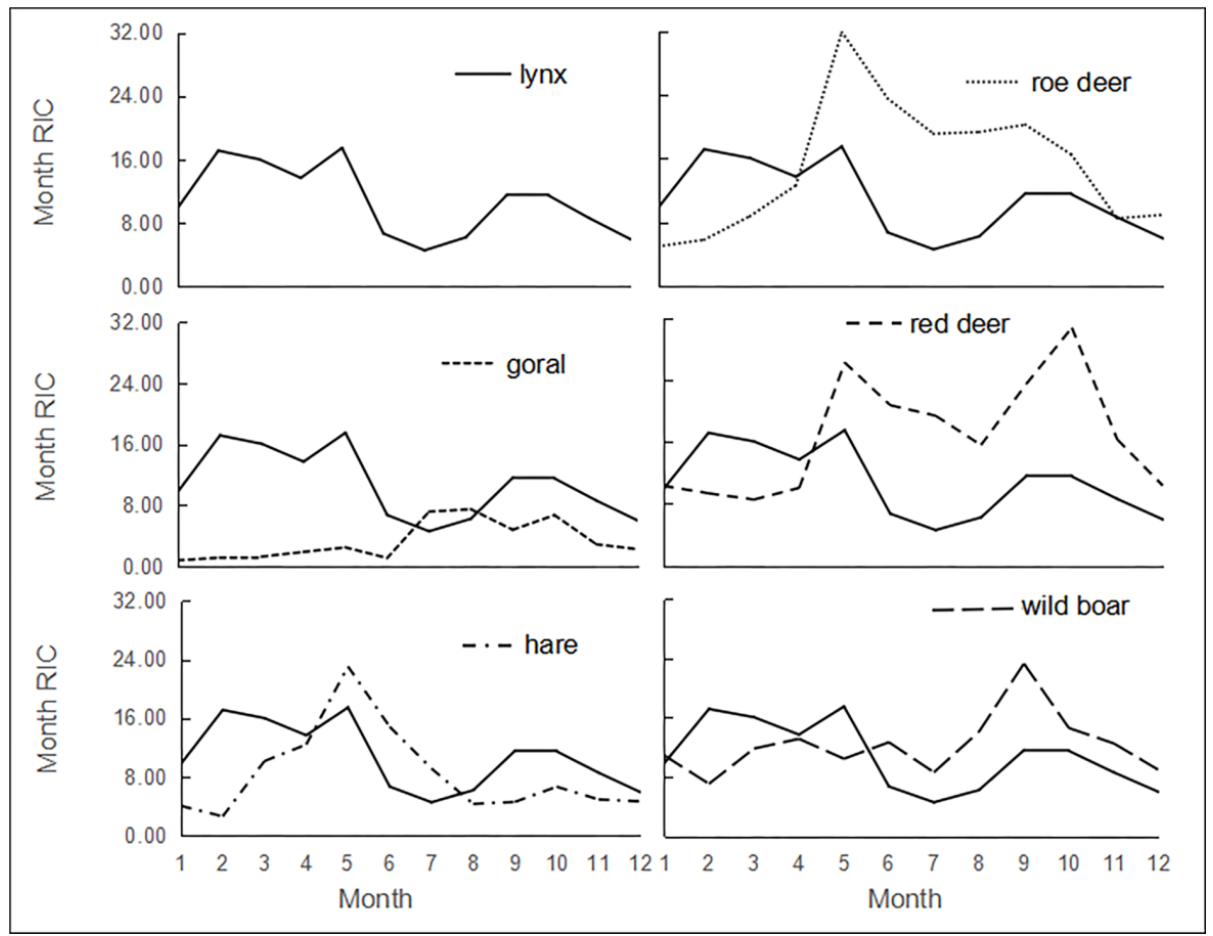

Figure 3. The monthly activity pattern of lynx and its main prey in Saihanwula. 


\subsubsection{Daily Activity Rhythm}

The daily activity rhythm of the lynx generally presented multiple peaks, with more active hours at night (as well as twilight) and inactive hours at midday in our study area. Although the Frideman's test showed that there were no significant differences among seasonal daily activity rhythms $(p=0.141>0.05)$, some visible variations were found (Figure 4$)$. The spring's active rhythm was the most nocturnal while the autumn rhythm was the most crepuscular. The active rhythms in the summer and winter were the transitional forms between them. Amongst all four seasons, lynx was the most nocturnal in spring, with all active peaks at night and the main peak at 21:00-22:00, the second one at 1:00-2:00, and the third one at 4:00-5:00. When it came to summer, the main peak moved forward to 16:00-17:00, with the second peak at 21:00-22:00, and the last peak at 4:00-6:00, which indicates that the rhythm distribution became more crepuscular. This variation tendency remained for the autumn pattern. The autumn pattern possessed the most active peak, lasting from 17:00 to 20:00, and an active period right before sunrise from 3:00 to 5:00. When winter arrived, the frequency of lynx activity increased in the afternoon and at night, with an unapparent peak before sunset at 16:00-17:00 (Figure 4). In general, the four seasons had four activity peaks at 1:00-2:00, 4:00-5:00, 17:00-19:00, and 20:00-22:00 (by time order).

Red deer $(r=0.644, p=0.001<0.01)$, hare $(r=0.712, p=0.000<0.01)$, wild boar $(r=0.563$, $p=0.004<0.01)$, badger $(r=0.669, p=0.000<0.01)$, and raccoon $\operatorname{dog}(r=0.730, p=0.000<0.01)$ were extremely synchronized with the lynx's total daily activity rhythm (Table 2 ). While the roe deer $(r=-0.220)$ and red fox $(r=-0.059)$ showed a timed avoidance to lynx to some extent, the relationship between the lynx and other sympatric prey species varied in different seasons. In spring, there were highly positive correlations between three species and the lynx, based on a Pearson correlation test: hare $(r=0.847, p=0.000<0.01)$, red deer $(r=0.588, p=0.002<0.01)$, and wild boar $(r=0.620, p=0.001$ $<0.01$ ), of which hare was highly synchronized with the lynx in its unimodal and nocturnal daily activity pattern. Although the three ungulates presented similar crepuscular activity patterns in spring, unlike red deer, roe deer $(r=-0.311)$ and goral $(r=-0.229)$ showed an active avoidance of lynx to some extent. In spite of the activity rhythm synchronization between ungulates and lynx during the sunrise period, the summer activity rhythms showed no significant relationships between the lynx and its five main types of prey. In autumn, the activity pattern of the lynx was positively related to that of red deer $(r=0.507, p=0.011<0.05)$, wild boar $(r=0.856, p=0.000<0.01)$, and roe deer $(r=0.507$, $p=0.011<0.05)$; the two deer species and the lynx were crepuscular, with peaks at sunrise and sunset. The negative correlation between the daily winter activity patterns of lynx and roe deer $(r=-0.421$, $p=0.041<0.05$ ) was remarkable, but the activity of the hare was positively correlated to that of the lynx $(r=0.460, p=0.024<0.05)$.

Table 2. Pearson correlation test between the lynx and its sympatric prey.

\begin{tabular}{|c|c|c|c|c|c|c|c|c|c|}
\hline \multicolumn{2}{|c|}{ Seasons } & \multirow{2}{*}{$\begin{array}{c}\begin{array}{c}\text { Roe } \\
\text { Deer }\end{array} \\
-0.311\end{array}$} & \multirow{2}{*}{$\begin{array}{c}\text { Goral } \\
-0.229\end{array}$} & \multirow{2}{*}{$\begin{array}{c}\begin{array}{c}\text { Red } \\
\text { Deer }\end{array} \\
0.588^{* *}\end{array}$} & \multirow{2}{*}{$\begin{array}{c}\text { Hare } \\
0.847^{* *}\end{array}$} & \multirow{2}{*}{$\begin{array}{c}\begin{array}{c}\text { Wild } \\
\text { Boar }\end{array} \\
0.620^{* *}\end{array}$} & \multirow[t]{2}{*}{ Badger } & \multirow[t]{2}{*}{$\begin{array}{c}\text { Raccoon } \\
\text { Dog }\end{array}$} & \multirow[t]{2}{*}{$\begin{array}{l}\text { Red } \\
\text { Fox }\end{array}$} \\
\hline Spring & $r$ & & & & & & & & \\
\hline & $p$ & 0.139 & 0.281 & 0.002 & 0.000 & 0.001 & & & \\
\hline \multirow{2}{*}{ Summer } & $r$ & 0.212 & 0.383 & 0.212 & 0.135 & 0.256 & & & \\
\hline & $p$ & 0.321 & 0.065 & 0.321 & 0.528 & 0.227 & & & \\
\hline \multirow{2}{*}{ Autumn } & $r$ & 0.507 * & 0.109 & 0.507 * & 0.400 & $0.856^{* *}$ & & & \\
\hline & $p$ & 0.011 & 0.611 & 0.011 & 0.053 & 0.000 & & & \\
\hline \multirow{2}{*}{ Winter } & $r$ & -0.421 * & -0.180 & 0.132 & 0.460 * & 0.098 & & & \\
\hline & $p$ & 0.041 & 0.400 & 0.537 & 0.024 & 0.648 & & & \\
\hline \multirow{2}{*}{ Total } & $r$ & -0.220 & 0.128 & $0.644^{* *}$ & $0.712^{* *}$ & $0.563 * *$ & $0.669^{* *}$ & 0.730 ** & -0.059 \\
\hline & $p$ & 0.302 & 0.552 & 0.001 & 0.000 & 0.004 & 0.000 & 0.000 & 0.784 \\
\hline
\end{tabular}




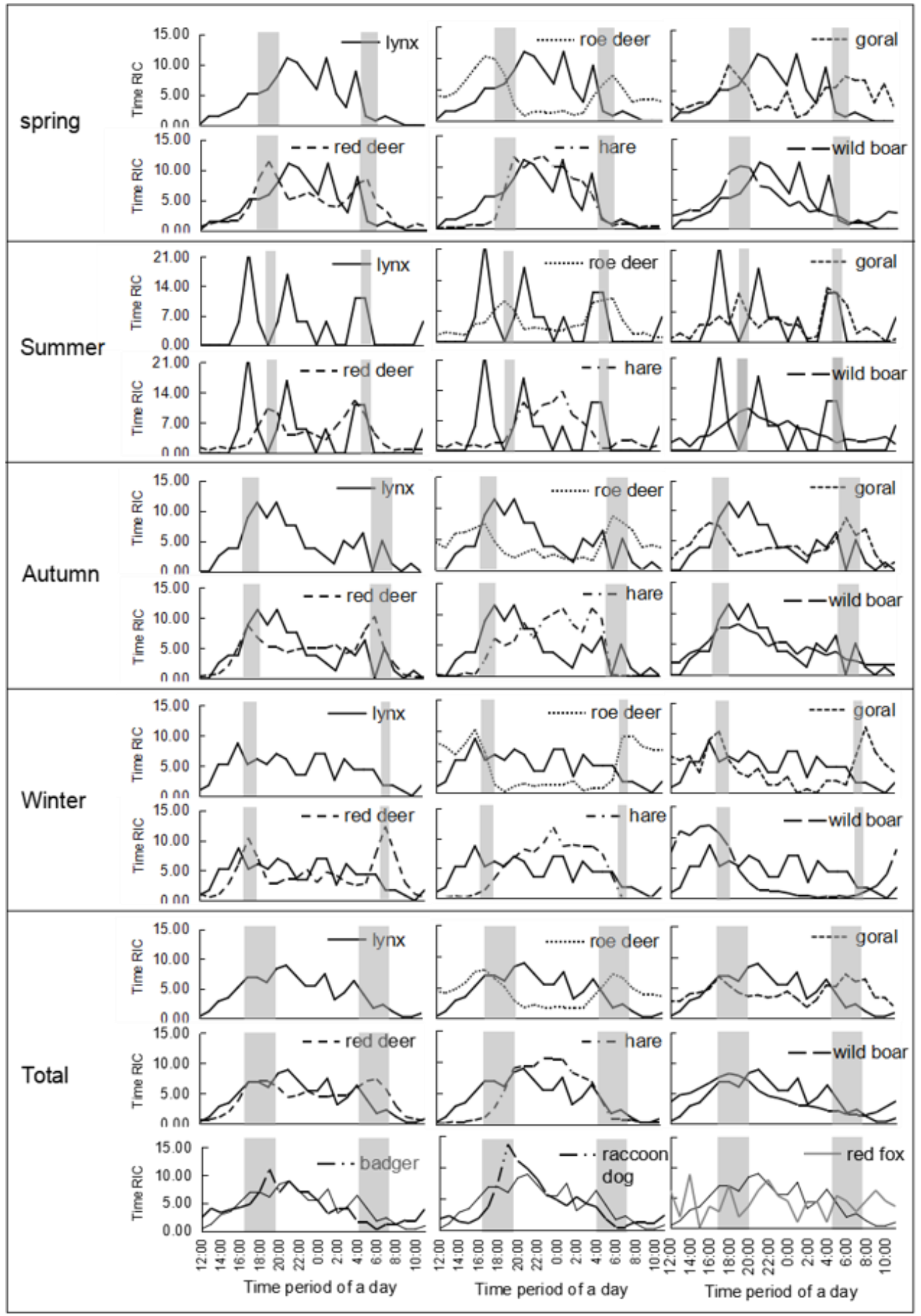

Figure 4. Daily activity rhythm of the lynx and sympatric prey in different seasons (grey bars show sunset and sunrise; data from https://richurimo.51240.com). 


\section{Discussion}

The onset of lynx population recovery in our study area occurred after the establishment of the reserve and the declaration of the relevant regulations on illegal hunting in 1997. Before that, there were only three records of lynx, two in 1987 and one in 1996 [32]. Our research group has been tracking local lynx population dynamics continuously since 2006 [25,27]. In 2006-2009, a snowy footprint tracking survey indicated that there were over seven individuals in the SS and QYS areas, which implied a minimum density of $6.66 / 100 \mathrm{~km}^{2}$. During 2010-2012, this number was confirmed through camera trapping in the SS area, with a minimum density of $12.18 / 100 \mathrm{~km}^{2}$. Combined with this study, a conclusion could be made that the lynx population in the Saihanwula nature reserve has been increasing since 2006. The density of the lynx was $1.32 \pm 0.151 / 100 \mathrm{~km}^{2}$ [30] in the northeast area of China, $1.00 \pm 0.70 / 100 \mathrm{~km}^{2}$ in the Changbaishan nature reserve, and $0.50 / 100 \mathrm{~km}^{2}$ in Xinjiang [29]. In comparison, the lynx has a considerably higher density in the Saihanwula nature reserve. In general, judging by population density along with breeding situation, the lynx population in the Saihanwula reserve has undergone restoration and reached an optimistically high population size. The reason for the low RIC and lack of a lynx family recorded in 2015 is because an illegal grazing case occurred in the reserve, and some of the cameras were destroyed by the herders.

The increase in the lynx population is possibly attributable to the recovery of ungulate prey after a feeding program initiated in 2009, where the nature reserve staff periodically offered nutrient mineral blocks to herbivores in the reserve. This forage implementation may provide informative empirical data for nature reserves aiming at large carnivore conservation through the restoration of prior prey.

The daily activity rhythms of wild cat species are usually nocturnal or crepuscular, such as with puma (Panthera onca), jaguar (Puma concolor), Iriomote cat (Prionailurus iriomotensis), and leopard cat (Prionailurus bengalensis) $[1,33,34]$. Species in the Lynx genus also accord with this conclusion, including the Eurasian lynx [35,36], Canadian lynx (Lynx canadensis) [37,38], and Iberian lynx (Lynx pardinus) [39]. The activity rhythms of carnivores are affected by a number of factors, including the moon phase, prey rhythms, inter-specific competition, gender, and reproductive phases [40-42]. Among these factors, prey abundance plays the most important role [1]. The active bouts of hunting during a predator's day usually synchronize with the schedules of their main prey to raise their hunting success rate $[43,44]$. The main prey species of lynx are hare and ungulates [17-19,45-49] with nocturnal or crepuscular activity rhythms, which explains why the lynx's daily activity patterns are nocturnal or crepuscular. For example, in north Scandinavia, lynx in different latitudinal areas adjusted their activity rhythms to synchronize with the main local ungulate species [35]. Through an analysis of 35 lynx feces samples in Saihanwula, the hare was found to be the most important prey, with 29 detections [26]; the hare's activity pattern was synchronized with lynx at the highest level (Table 2), followed by the roe deer, with four detections [26]. However, the activity rhythm of roe deer had no synchronization and even showed an avoidance of lynx based on this study (Figure 4 and Table 2). The reason for this result is possibly the high population abundance of roe deer, with a total yearly RIC of 129.16, which was over 11 times of that lynx. The abundance was so high that it was unnecessary for lynx to synchronize their activity rhythms with roe deer to increase hunting success. Both red deer and wild boar had only one detection in the fecal analysis [26], which indicated that they were not the main prey but more occasional choices for lynx under circumstance of insufficient hare or roe deer. Compared with hare and roe deer, red deer and wild boar are less suitable prey with a large size and aggressiveness. Thus, there was no need for them to avoid lynx, and their active periods highly overlapped with those of the lynx.

There was obvious seasonal variation in the activity rhythm of the lynx [36,37], and this study showed the same result (Figure 4). This variation may relate to the prey, thermoregulation, sex, or breeding status [36,37]. Some reports show that lynx changed their main prey during different seasons. In the warm seasons, lynx prefer small prey, while in cold seasons, they mainly prey on larger animals [50,51]. The fecal analyses in Saihanwula agreed with this conclusion [26]. Thus, in the most active period of hare during spring in Saihanwula (Figure 3), the lynx exhibited a totally nocturnal 
pattern to synchronize with the hare's activity rhythm (Figure 4 and Table 2). In autumn, the lynx became more crepuscular to synchronize with the roe deer (Figure 4 and Table 2), which showed a relatively high activity pattern (Figure 3). Environmental temperature may play a partial role in the seasonal differences of the lynx's activity rhythms. Studies on Canadian lynx and Iberian lynx revealed a pronounced increase of diurnal activity in winter [37,38,52], but this time budget shift has not yet been reported for Eurasian lynx [36,53]. Our study provides solitary proof that Eurasian lynx evidently increase their activity in the afternoon during winter (Figure 4), which may result in lower energy expenditure under cold temperatures.

The co-existence of top-predators and meso-predators is always related to niche segregation [39]. Top predators might suppress the abundance of meso-predators by killing them [54]. Red fox are often reported to be killed by lynx in different areas $[55,56]$. The red fox preys mainly on rodent and hare and has a highly overlapping food niche with the lynx [57], which may indicate a food competition with the lynx and a risk of being killed by the lynx. To co-exist with lynx, one of its strategies is to compromise its activity times [58]. Our results may also indicate a similar situation-that the abundance of red fox in our study area was low, with an independent capture number of 115; and a negative correlation in daily activity pattern (Table 2). The badger and raccoon dog in Saihanwula did not show any activity avoidance of the lynx. The badger's main prey are insects and plants in Saihanwula [59], which means its food niche does not overlap with that of the lynx. Thus, they do not need to occupy a different time niche from the lynx to co-exist with the lynx. Another hypothesis is that the badger is just indifferent and shows no avoidance of the lynx, even with the same main prey in Spain [58]. The raccoon dog preys mainly on ground nesting bird and rodent species, which overlaps with the lynx to a small degree. However, its activity rhythm preset shows no avoidance of the lynx, so there might be other ways for it to escape the lynx's predation.

There are some drawbacks to this study. With the limited cameras we were not able to cover the whole reserve. Thus, there might be lynx individuals that have not been pictured. Moreover, since the lynx was our study priority, there is the possibility that impacts from other important carnivore species, such as the wolf, have been underestimated or ignored. Other than that, the camera trapping data for the summer were insufficient, as we had to remove some of our cameras during this time to prevent the cameras from being destroyed or stolen by herders or poachers. Current data on the photo identification of the lynx in Saihanwula is not enough for further research, such as population size estimation through the capture-recapture model and home range calculation. We hope to conduct studies at a deeper level based on photo IDs. For the predator-prey relationship in Saihanwula, the next step is to study spatial interactions to construct a spatial-temporal network of mammal communities, which will enable us to have a more comprehensive view of the ecosystem where the lynx lives.

\section{Conclusions}

The present study found that the Eurasian lynx population is recovering. We speculate that the restoration of prey abundance is the basic causation, although it is not possible to demonstrate this from the presently available data. The activity pattern and daily rhythm of the lynx followed the pace of different prey resources seasonally. Red foxes avoided direct conflict with, and predation risk from, the lynx by adjusting its activity pulse and maintaining its co-existence with the top predator. The camera trapping technique is suitable to determine population trends and the behavioral monitoring of lynx because our animals used the camera fixing trees as convenient scent marking sites. However, we still could not estimate the exact population of the lynx in the study region with the present method of camera trapping because our sample lynx lacked any significant body patterns. We hope to tackle this problem with non-invasive sampling DNA identification, which may provide some insights into the population structures and kinship relations of lynx. 
Supplementary Materials: The following are available online at http://www.mdpi.com/2076-2615/9/11/864/s1, Figure S1: Six photos showing the inner side of forelimbs. (a) Two black dots on left forelimb; (b) One bigger black dot on left forelimb; (c) No obvious dot on right forelimb; (d) Three heavy black dots on left forelimb; (e) "V" type black mark on left forelimb; (f) Three light black dots on left forelimb.

Author Contributions: Investigation, S.T., X.L., D.M., W.B. (Wuliji Bao), and C.X.; writing-original draft preparation, X.T. and S.T.; writing—review and editing, F.G.; project administration, W.B. (Weidong Bao).

Funding: This research was funded by the State Forestry and Grassland Administration of China, grant number 2013-LYSJWT-33.

Acknowledgments: We are grateful to the staff from the Saihanwula national nature reserve for checking the camera traps and for their field support during the study years. Kind thanks to the three anonymous reviewers for their helpful comments and suggestions to the original manuscript.

Conflicts of Interest: The authors declare no conflict of interest. The funders had no role in the design of the study; in the collection, analyses, or interpretation of data; in the writing of the manuscript, or in the decision to publish the results.

\section{References}

1. Harmsen, B.J.; Foster, R.J.; Silver, S.C.; Ostro, L.E.T.; Doncaster, C.P. Jaguar and puma activity patterns in relation to their main prey. Mamm. Biol. 2011, 76, 320-324. [CrossRef]

2. Sunquist, M.; Sunquist, F. Wild Cats of the World; University of Chicago Press: Chicago, IL, USA, $2002 ;$ p. 452.

3. Griffiths, M.; Van Schaik, C.P. Camera-trapping: A new tool for the study of elusive rain forest animals. Trop. Biodivers. 1993, 1, 131-135.

4. Karanth, K.U.; Chundawat, R.S.; Nichols, J.D.; Kumar, N.S. Estimation of tiger densities in the tropical dry forests of Panna, Central India, using photographic capture-recapture sampling. Anim. Conserv. 2004, 7, 285-290. [CrossRef]

5. Eléanor, B.; Daniel, P. Trapping Elusive Cats: Using Intensive Camera Trapping to Estimate the Density of a Rare African Felid. PLoS ONE 2015, 10, e0142508.

6. Buzzard, P.J.; MaMing, R.; Turghan, M.; Xiong, J.; Zhang, T. Presence of the snow leopard Panthera uncia confirmed at four sites in the Chinese Tianshan Mountains. Oryx 2017, 51, 594-596. [CrossRef]

7. Defeng, B.; Pengju, C.; Luciano, A.; Lhaba, C.; Qian, L.; Kun, S. Assessment of habitat suitability of the snow leopard (Panthera uncia) in Qomolangma National Nature Reserve based on MaxEnt modeling. Zool. Res. 2018, 39, 373-386. [CrossRef]

8. Buzzard, P.J.; Xueyon, L.; Bleisch, W.V. The status of snow leopards Panthera uncia, and high altitude use by common leopard P. pardus, in north-west Yunnan, China. Oryx 2017, 51, 587-589. [CrossRef]

9. Chen, P.; Gao, Y.; Wang, J.; Pu, Q.; Lhaba, C.; Hu, H.; Xu, J.; Shi, K. Status and conservation of the Endangered snow leopard Panthera uncia in Qomolangma National Nature Reserve, Tibet. Oryx 2016, 51, 590-593. [CrossRef]

10. Li, Z.; Wang, T.; Smith, J.L.D.; Feng, R.; Feng, L.; Mou, P.; Ge, J. Coexistence of two sympatric flagship carnivores in the human-dominated forest landscapes of Northeast Asia. Landsc. Ecol. 2019, 34, 291-305. [CrossRef]

11. Yang, H.; Han, S.; Xie, B.; Mou, P.; Kou, X.; Wang, T.; Ge, J.; Feng, L. Do prey availability, human disturbance and habitat structure drive the daily activity patterns of Amur tigers (Panthera tigris altaica)? J. Zool. 2018, 307, 131-140. [CrossRef]

12. Boutros, D.; Breitenmoser-Würsten, C.; Zimmermann, F.; Ryser, A.; Molinari-Jobin, A.; Capt, S.; Güntert, M.; Breitenmoser, U. Characterisation of Eurasian lynx Lynx lynx den sites and kitten survival. Wildl. Biol. 2007, 13, 417-429. [CrossRef]

13. Podgorski, T.; Schmidt, K.; Kowalczyk, R.; Gulczynska, A. Microhabitat selection by Eurasian lynx and its implications for species conservation. Acta Theriol. 2008, 53, 97-110. [CrossRef]

14. Kramer-Schadt, S.; Revilla, E.T.; Breitenmoser, U. Fragmented landscapes, road mortality and patch connectivity: Modelling influences on the dispersal of Eurasian lynx. J. Appl. Ecol. 2004, 41, 711-723. [CrossRef]

15. Schadt, S.; Knauer, F.; Kaczensky, P.; Revilla, E.; Wiegand, T.; Trepl, L. Rule-Based Assessment of Suitable Habitat and Patch Connectivity for the Eurasian Lynx. Ecol. Appl. 2002, 12, 1469. [CrossRef] 
16. Stenseth, N.C.; Falck, W.; Bjornstad, O.N.; Krebs, C.J. Population regulation in snowshoe hare and Canadian lynx: Asymmetric food web configurations between hare and lynx. Proc. Natl. Acad. Sci. USA 1997, 94, 5147-5152. [CrossRef] [PubMed]

17. Okarma, H.; Jędrzejewski, W.; Schimidt, K. Predation of Eurasian lynx on roe deer and red deer in Białowieża Primeval Forest, Poland. Acta Theriol. 1997, 42, 203-224. [CrossRef]

18. Molinari-Jobin, A.; Zimmermann, F.; Ryser, A.; Breitenmoser-Würsten, C.; Capt, S.; Breitenmoser, U.; Molinari, P.; Haller, H.; Eyholzer, R. Variation in diet, prey selectivity and home-range size of Eurasian lynx Lynx lynx in Switzerland. Wildl. Biol. 2007, 13, 393-405. [CrossRef]

19. Schmidt, K. Behavioural and spatial adaptation of the Eurasian lynx to a decline in prey availability. Acta Theriol. 2008, 53,1-16. [CrossRef]

20. Vik, J.O.; Brinch, C.N.; Boutin, S.; Stenseth, N.C. Interlinking hare and lynx dynamics using a century's worth of annual data. Popul. Ecol. 2008, 50, 267-274. [CrossRef]

21. Breitenmoser, U.; Breitenmoser-Würsten, C.; Okarma, H. Action Plan for the Conservation of the Eurasian Lynx (Lynx lynx) in Europe; Council of Europe: Strasbourg, France, 2000.

22. Chinese State Forestry Administration. The Resource Survey of State Key Terrestrial Wildlife in China; China Forestry Publishing House: Beijing, China, 2008; pp. 255-257.

23. Gao, Y. Fauna Sinica, Mammalia, Volune 8: Carnivora; A.S. Editorial Committee of Fauna Sinica; Science Press: Beijing, China, 1987; pp. 335-336.

24. Smith, A.T.; Xie, Y. A Guide to the Mammals of China Guide to the Mammals of China; Hunan Education Press: Changsha, China, 2009; p. 375.

25. Zhou, X.; Bao, Q.; Song, J.; Xia, W.; Menhedaila; Zhang, S.; Yang, Y.; Bao, W. Individual identification and behavior study of Eurasian lynx(Lynx lynx) based on camera trapping technique. J. Biol. 2015, 32, $20-23$. [CrossRef]

26. Tan, S.; Jiang, X.; Zhang, G.; Zhang, J.; Men, H.; Han, Y.; Bao, W. Preliminary Analysis on the Diet Composition of Eurasian Lynx at Saihanwula National Nature Reserve. Chin. J. Zool. 2019, 54, 151-158. [CrossRef]

27. Zhang, L. Population Ecology of Eurasian ( $\operatorname{lyn} x \operatorname{lynx})$ in Saihanwual Nature Reserve, Inner Mongolia. Master's Thesis, Beijing Forestry University, Beijing, China, 2010.

28. Zhou, X.; Song, J.; Wang, F.; Xia, W.; Wu, L.; Zhang, Z.; Bao, W. The application of extracting DNA from noninvasive sample in feline species identification. Acta Theriol. Sin. 2015, 35, 110-118. [CrossRef]

29. Abilimit, A. Study on ecology, distribution, resources and protection strategies of Lynx lynx in Xinjiang. Arid Zone Res. 1998, 15, 38-43.

30. Tian, J.; Li, G.; Sun, H. Current Status and Protection of Felis Lynx Population in the Northeast of China. Spec. Wild Econ. Anim. Plant Res. 2002, 1, 59-61. [CrossRef]

31. Piao, Z.; Sui, Y.; Cui, Z.; Zhang, G.; Wang, Q.; Fu, X. The History and Current Status of Felid Population in Changbai Mountain Nature Reserve. Chin. J. Zool. 2011, 46, 78-84. [CrossRef]

32. Yong, S.; Xing, L.; Li, G. Biodivistity of Saihanwula National Natrure Reserve; Inner Mongolia University Press: Huhhot, China, 2011; pp. 1-506.

33. Azlan, J.M.; Sharma, D.S. The diversity and activity patterns of wild felids in a secondary forest in Peninsular Malaysia. Oryx 2006, 40, 36-41. [CrossRef]

34. Schmidt, K.; Nakanishi, N.; Izawa, M.; Okamura, M.; Watanabe, S.; Tanaka, S.; Doi, T. The reproductive tactics and activity patterns of solitary carnivores: The Iriomote cat. J. Ethol. 2008, 27, 165. [CrossRef]

35. Heurich, M.; Hilger, A.; Küchenhoff, H.; Andrén, H.; Bufka, L.; Krofel, M.; Mattisson, J.; Odden, J.; Persson, J.; Rauset, G.R. Activity patterns of Eurasian lynx are modulated by light regime and individual traits over a wide latitudinal range. PLoS ONE 2014, 9, e114143. [CrossRef]

36. Podolski, I.; Belotti, E.; Bufka, L.; Reulen, H.; Heurich, M. Seasonal and daily activity patterns of free-living Eurasian lynx Lynx lynx in relation to availability of kills. Wildl. Biol. 2013, 19, 69-77. [CrossRef]

37. Kolbe, J.A.; Squires, J.R. Circadian activity patterns of canada lynx in western Montana. J. Wildl. Manag. 2007, 71, 1607-1611. [CrossRef]

38. Parker, G.R.; Maxwell, J.W.; Morton, L.D.; Smith, G.E. The ecology of the Lynx (Lynx canadensis) on Cape Breton Island. Can. J. Zool. 1983, 61, 770-786. [CrossRef]

39. Fedriani, J.M.; Palomares, F.; Delibes, M. Niche relations among three sympatric Mediterranean carnivores. Oecologia 1999, 121, 138-148. [CrossRef] [PubMed] 
40. Bitetti, M.S.D.; Paviolo, A.; De Angelo, C.D. Density, habitat use and activity patterns of ocelots (Leopardus pardalis) in the Atlantic Forest of Misiones, Argentina. Proc. Zool. Soc. Lond. 2010, 270, 153-163. [CrossRef]

41. Hayward, M.W.; Slotow, R. Temporal partitioning of activity in large african carnivores: Tests of multiple hypotheses. S. Afr. J. Wildl. Res. 2009, 39, 109-125. [CrossRef]

42. Odden, M.; Wegge, P. Spacing and activity patterns of leopards Panthera pardus in the Royal Bardia National Park, Nepal. Wildl. Biol. 2007, 11, 145-152. [CrossRef]

43. Zielinski, W.J.; Spencer, W.D.; Barrett, R.H. Relationship between Food Habits and Activity Patterns of Pine Martens. J. Mammal. 1983, 64, 387-396. [CrossRef]

44. Ferguson, J.W.H.; Galpin, J.S.; Wet, M.J.D. Factors affecting the activity patterns of black-backed jackals Canis mesomelas. J. Zool. 1988, 214, 55-69. [CrossRef]

45. Keim, J.L.; Lele, D.W.R. Predators choose prey over prey habitats: Evidence from a lynx-hare system. Ecol. Appl. 2011, 21, 1011-1016. [CrossRef]

46. Sidorovich, V.E. Relationship between prey availability and population dynamics of the Eurasian lynx and its diet in northern Belarus. Acta Theriol. 2006, 51, 265-274. [CrossRef]

47. Kauhala, K.; Helle, P. The interactions of predator and hare populations in Finland-A study based on wildlife monitoring counts. Ann. Zool. Fenn. 2000, 37, 151-160.

48. Remmen, J. Risk of Lynx Predation in Roe Deer Depends on Habitat Structure. Master's Thesis, Norwegian University of Life Sciences, Oslo, Norway, 2012.

49. Krofel, M.; Jerina, K.; Kljun, F.; Kos, I.; Potočnik, H.; Ražen, N.; Zor, P.; Žagar, A. Comparing patterns of human harvest and predation by Eurasian lynx Lynx lynx on European roe deer Capreolus capreolus in a temperate forest. Eur. J. Wildl. Res. 2014, 60, 11-21. [CrossRef]

50. Odden, J.; Linnell, J.D.C.; Andersen, R. Diet of Eurasian lynx, Lynx lynx, in the boreal forest of southeastern Norway: The relative importance of livestock and hares at low roe deer density. Eur. J. Wildl. Res. 2006, 52, 237-244. [CrossRef]

51. Krofel, M.; Huber, D.; Kos, I. Diet of Eurasian lynx Lynx lynx in the northern Dinaric Mountains (Slovenia and Croatia). Acta Theriol. 2011, 56, 315-322. [CrossRef]

52. Beltran, J.; Delibes, M. Environmental determinants of cireadian activity of free-ranging Iberian lynxes. J. Mammal. 1994, 75, 382-393. [CrossRef]

53. Schmidt, K. Variation in daily activity of the free-living Eurasian lynx (Lynx lynx) in Białowieża Primeval Forest, Poland. Proc. Zool. Soc. Lond. 1999, 249, 417-425.

54. Greenville, A.C.; Wardle, G.M.; Tamay, B.; Dickman, C.R. Bottom-up and top-down processes interact to modify intraguild interactions in resource-pulse environments. Oecologia 2014, 175, 1349-1358. [CrossRef]

55. Helldin, J.O.; Liberg, O.; Glöersen, G. Lynx (Lynx lynx) killing red foxes (Vulpes vulpes) in boreal Sweden ? frequency and population effects. J. Zool. 2006, 270, 657-663. [CrossRef]

56. Jobin, A.; Molinari, P.; Breitenmoser, U. Prey spectrum, prey preference and consumption rates of Eurasian lynx in the Swiss Jura Mountains. Acta Theriol. 2000, 45, 243-252. [CrossRef]

57. Zhang, Y. Food Habits and Habitat Selection of Five Canivoras in Saihanwula Nature Reserve. Master's Thesis, Beijing Forestry University, Beijing, China, 2008.

58. Palomares, F.; Ferreras, P.; Fedriani, J.M.; Delibes, M. Spatial relationships between Iberian lynx and other carnivores in an area of south-western Spain. J. Appl. Ecol. 1996, 33, 5-13. [CrossRef]

59. Zhang, L.; Wang, A.; Yuan, L.; Bao, W.; Yang, Y. Preliminary comparison of diet composition of four small sized carnivores at Saihanwula nature reserve, Inner Mongolia. Acta Theriol. Sin. 2011, 31, 1-8. [CrossRef]

(C) 2019 by the authors. Licensee MDPI, Basel, Switzerland. This article is an open access article distributed under the terms and conditions of the Creative Commons Attribution (CC BY) license (http://creativecommons.org/licenses/by/4.0/). 